\title{
Runway behavior of the rat as a function of intersubject reward contingencies and constancy of daily reward schedule?
}

\section{H. WAYNE I.UDVIGSON, Texas (hristian University. Fort Worth, Tex. 76129}

This study explored the methodological implications of a source of experimental contamination, the goal events and, presumably, consequent odors of preceding animals. Rats received reward $(R)$ and nonreward $(N)$ in double-alternation sequences, with the experimental treatments resulting from variation in the particular sequences administered to members of a squad. The results suggested that differential odors cxuded by preceding $S s$ on $R$ and $N$ trials can serve as discriminative cues signalling $R$ or $N$, but that the odor cue from the immediately preceding trial could be neutralized by prior odors of the other kind. Constancy of schedule cnhanced the discrimination.

Recent studies have indicated the importance, for a rat in an alley-type maze, of the goal events and the consequent behavio of the animals which precede the given $S$ in the maze. For example, (1) although $S s$ receive the same reward condition in two alleys they nevertheless may display differential behavior in these alleys if preceding $S s$ are differentially rewarded (McHose \& Ludvigson, 1966), and (2) pattemed responding can be produced if the inter-S reward contingencies are such that rewards and nonrewards for preceding $S s$ are followed consistently by reward $(R)$ and nonreward $(N)$, respectively, for a given $S$ (Ludvigson \& Sytsma, 1967).

Such data are consistent with the interpretation that on $\mathbf{R}$ and $\mathrm{N}$ trials rats excrete differential odors which persist until succeeding trials. For the succeeding animal such odors may elicit a relatively weak (unconditioned) reaction such that traversal of an alley is slowed following $N$ trials, and/or serve as discriminative cues for differential behavior dependent upon the inter-S reward contingencies.

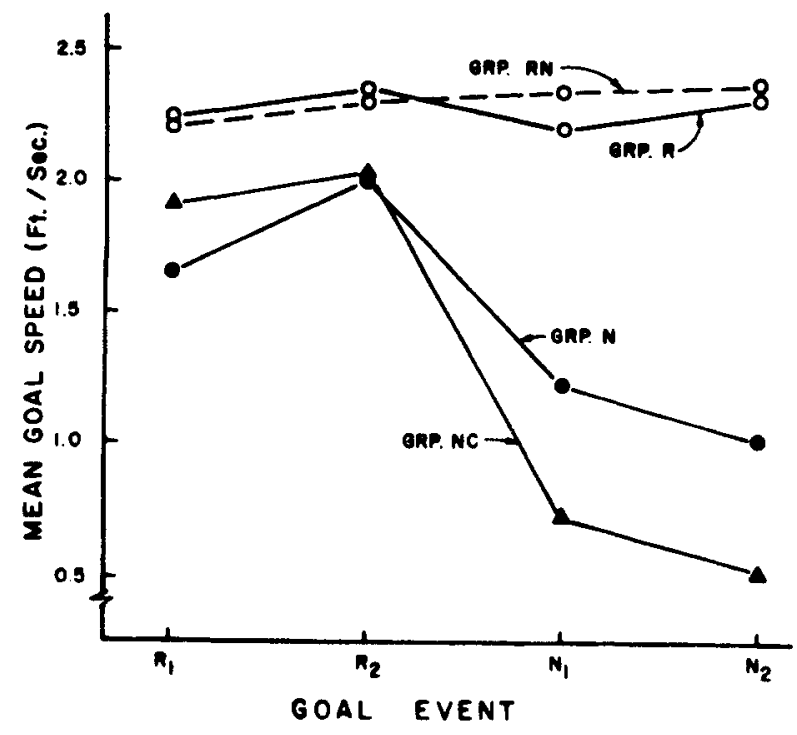

Fig. 1. Mean goal speed over Days 9-12 of acquisition as a function of goal events. The first $\mathbf{R}$ trial of a double alternation cycle is designated by $R I$ and the first $N$ trial is designated $N I$. etc

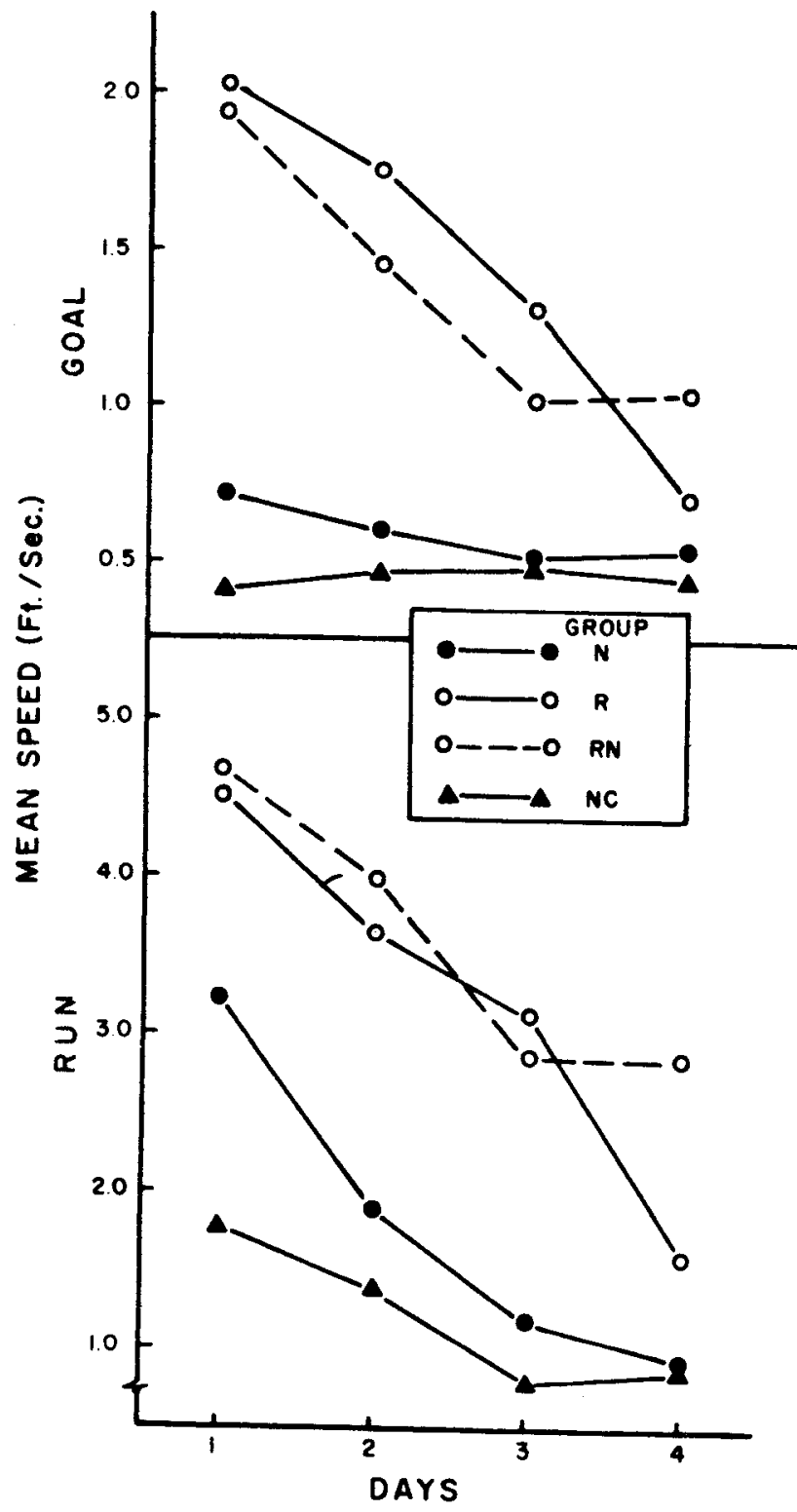

Fig. 2. Mean goal and run speed over the four days of extinction.

The present study replicated and extended the work on inter-S reward contingencies, and assessed the relevance, both for pattemed responding and for extinction, of a constant vs a changing daily schedule of $\mathrm{R}$ and $\mathrm{N}$ trials.

\section{SUBJECTS}

Furty-four naive, fernale Sprague-Dawley rats, 85 days of age on Day 1 , served as.Ss.

\section{APPARATUS}

A 7-ft straight runway (see Ludvigson \& Sytsma, 1967) provided three measures of speed of traversal. start, run. and goal speeds. expressed in $\mathrm{fi} / \mathrm{sec}$.

DESIGN ANDPROCEDURE

All Ss received 12 Jays of acquisition in which $R$ and $N$ were administeled in double alternation patterns, and four days of extenction. 
Table 1

Schedule of Reward (R) and Nonreward (N) over a Four-Day Cycle. S1 through S11, in that onder, received Trial 1 , then Trial 2 in the same order, etc.

\begin{tabular}{|c|c|c|c|c|}
\hline $\begin{array}{l}\mathbf{G} \\
\mathbf{R} \\
\mathbf{0} \\
\mathbf{U}\end{array}$ & Trial & $\begin{array}{l}{ }_{\text {Day }} 2 \\
\text { Trial }\end{array}$ & $\begin{array}{r}3 \\
\text { Trial }\end{array}$ & ${ }_{\text {Trial }}^{4}$ \\
\hline & 12345678 & $\begin{array}{llllllll}1 & 2 & 3 & 4 & 5 & 6 & 7 & 8\end{array}$ & $\begin{array}{llllllll}1 & 2 & 3 & 4 & 5 & 6 & 7 & 8 \\
\end{array}$ & 12345678 \\
\hline $\begin{array}{c}\text { S1 } \\
\text { S2 } \\
\mathbf{N} . \\
\cdot \\
\cdot \\
\text { S1 I }\end{array}$ & $\begin{array}{l}\begin{array}{llllllll}R & R & N & N & R & R & N & N \\
R & R & N & N & R & R & N & N \\
\text { (Same schedule for all Ss) }\end{array} \\
\text { (S) }\end{array}$ & $\begin{array}{llllllll}\mathbf{R} & \mathbf{R} & \mathbf{N} & \mathbf{N} & \mathbf{R} & \mathbf{R} & \mathbf{N} & \mathbf{N} \\
\mathbf{R} & \mathbf{R} & \mathbf{N} & \mathbf{N} & \mathbf{R} & \mathbf{R} & \mathbf{N} & \mathbf{N}\end{array}$ & $\begin{array}{llllllll}\mathbf{N} & \mathbf{N} & \mathbf{R} & \mathbf{R} & \mathbf{N} & \mathbf{N} & \mathbf{R} & \mathbf{R} \\
\mathbf{N} & \mathbf{N} & \mathbf{R} & \mathbf{R} & \mathbf{N} & \mathbf{N} & \mathbf{R} & \mathbf{R}\end{array}$ & $\begin{array}{lllllllll}\mathbf{N} & \mathbf{N} & \mathbf{R} & \mathbf{R} & \mathbf{N} & \mathbf{N} & \mathbf{R} & \mathbf{R} \\
\mathbf{N} & \mathbf{N} & \mathbf{R} & \mathbf{R} & \mathbf{N} & \mathbf{N} & \mathbf{R} & \mathbf{R}\end{array}$ \\
\hline $\begin{array}{c}\text { S1 } \\
\text { S2 } \\
\text { S3 } \\
\text { S4 } \\
\text { S5 } \\
\text { R. } \\
\cdot \\
\text { S11 } \\
\end{array}$ & $\begin{array}{llllllll}R & R & N & N & R & R & N & N \\
N & N & R & R & N & N & R & R \\
R & R & N & N & R & R & N & N \\
N & N & R & R & N & N & R & R \\
R & R & . & . & \text {.etc. } & & \end{array}$ & $\begin{array}{llllllll}R & R & N & N & R & R & N & N \\
N & N & R & R & N & N & R & R \\
R & R & N & N & R & R & N & N \\
N & N & R & R & N & N & R & R\end{array}$ & $\begin{array}{llllllll}\mathbf{N} & \mathbf{N} & \mathbf{R} & \mathbf{R} & \mathbf{N} & \mathbf{N} & \mathbf{R} & \mathbf{R} \\
\mathbf{R} & \mathbf{R} & \mathbf{N} & \mathbf{N} & \mathbf{R} & \mathbf{R} & \mathbf{N} & \mathbf{N} \\
\mathbf{N} & \mathbf{N} & \mathbf{R} & \mathbf{R} & \mathbf{N} & \mathbf{N} & \mathbf{R} & \mathbf{R} \\
\mathbf{R} & \mathbf{R} & \mathbf{N} & \mathbf{N} & \mathbf{R} & \mathbf{R} & \mathbf{N} & \mathbf{N}\end{array}$ & $\begin{array}{llllllll}\mathbf{N} & \mathbf{N} & \mathbf{R} & \mathbf{R} & \mathbf{N} & \mathbf{N} & \mathbf{R} & \mathbf{R} \\
\mathbf{R} & \mathbf{R} & \mathbf{N} & \mathbf{N} & \mathbf{R} & \mathrm{R} & \mathbf{N} & \mathbf{N} \\
\mathbf{N} & \mathbf{N} & \mathbf{R} & \mathbf{R} & \mathbf{N} & \mathbf{N} & \mathbf{R} & \mathbf{R} \\
\mathbf{R} & \mathbf{R} & \mathbf{N} & \mathbf{N} & \mathrm{R} & \mathbf{R} & \mathbf{N} & \mathbf{N}\end{array}$ \\
\hline $\begin{array}{r}\text { S1 } \\
\text { S2 } \\
\text { S3 } \\
\text { S4 } \\
\text { S5 } \\
\text { S6 } \\
\text { RNS7 } \\
\text { S8 } \\
\text { S9 } \\
\text { S10 } \\
\text { S11 } \\
\end{array}$ & $\begin{array}{llllllll}R & R & N & N & R & N & N \\
R & R & N & N & R & R & N & N \\
N & N & R & N & R & R \\
N & N & R & N & N & R \\
\text { (Same as } & \text { (a) } \\
\text { (ame as S2) } & & \\
\text { (Same as S3) } \\
\text { (Same as S4) } \\
\text { (Same as S1) } \\
\text { (Same as S2) } \\
\text { (Same as S3) } \\
\end{array}$ & $\begin{array}{llllllll}\mathbf{R} & \mathbf{R} & \mathbf{N} & \mathbf{N} & \mathbf{R} & \mathbf{R} & \mathbf{N} & \mathbf{N} \\
\mathbf{N} & \mathbf{N} & \mathbf{R} & \mathbf{R} & \mathbf{N} & \mathbf{N} & \mathbf{R} & \mathbf{R} \\
\mathbf{N} & \mathbf{N} & \mathbf{R} & \mathbf{R} & \mathbf{N} & \mathbf{N} & \mathbf{R} & \mathbf{R} \\
\mathbf{R} & \mathbf{R} & \mathbf{N} & \mathbf{N} & \mathbf{R} & \mathbf{R} & \mathbf{N} & \mathbf{N}\end{array}$ & $\begin{array}{llllllll}\mathbf{N} & \mathbf{N} & \mathbf{R} & \mathbf{R} & \mathbf{N} & \mathbf{N} & \mathbf{R} & \mathbf{R} \\
\mathbf{N} & \mathbf{N} & \mathbf{R} & \mathbf{R} & \mathbf{N} & \mathbf{N} & \mathbf{R} & \mathbf{R} \\
\mathbf{R} & \mathbf{R} & \mathbf{N} & \mathbf{N} & \mathbf{R} & \mathbf{R} & \mathbf{N} & \mathbf{N} \\
\mathbf{R} & \mathbf{R} & \mathbf{N} & \mathbf{N} & \mathbf{R} & \mathbf{R} & \mathbf{N} & \mathbf{N}\end{array}$ & $\begin{array}{llllllll}\mathbf{N} & \mathbf{N} & \mathbf{R} & \mathbf{R} & \mathbf{N} & \mathbf{N} & \mathbf{R} & \mathbf{R} \\
\mathbf{R} & \mathbf{R} & \mathbf{N} & \mathbf{N} & \mathbf{R} & \mathbf{R} & \mathbf{N} & \mathbf{N} \\
\mathbf{R} & \mathbf{R} & \mathbf{N} & \mathbf{N} & \mathbf{R} & \mathbf{R} & \mathbf{N} & \mathbf{N} \\
\mathbf{N} & \mathbf{N} & \mathbf{R} & \mathbf{R} & \mathbf{N} & \mathbf{N} & \mathbf{R} & \mathbf{R}\end{array}$ \\
\hline $\begin{array}{l}\text { S1 } \\
\text { S2 }\end{array}$ & $\begin{array}{llllllll}R & R & \mathbf{N} & \mathbf{N} & \mathbf{R} & \mathbf{R} & \mathbf{N} & \mathbf{N} \\
\mathbf{R} & \mathbf{R} & \mathbf{N} & \mathbf{N} & \mathbf{R} & \mathbf{R} & \mathbf{N} & \mathbf{N}\end{array}$ & $\begin{array}{llllllll}\mathbf{R} & \mathbf{R} & \mathbf{N} & \mathbf{N} & \mathbf{R} & \mathbf{R} & \mathbf{N} & \mathbf{N} \\
\mathbf{R} & \mathbf{R} & \mathbf{N} & \mathbf{N} & \mathbf{R} & \mathbf{R} & \mathbf{N} & \mathbf{N}\end{array}$ & $\begin{array}{llllllll}\mathbf{R} & \mathbf{R} & \mathbf{N} & \mathbf{N} & \mathbf{R} & \mathbf{R} & \mathbf{N} & \mathbf{N} \\
\mathbf{R} & \mathbf{R} & \mathbf{N} & \mathbf{N} & \mathbf{R} & \mathbf{R} & \mathbf{N} & \mathbf{N}\end{array}$ & $\begin{array}{llllllll}R & R & \mathbf{N} & \mathbf{N} & \mathbf{R} & \mathbf{R} & \mathbf{N} & \mathbf{N} \\
\mathbf{R} & \mathbf{R} & \mathbf{N} & \mathbf{N} & \mathbf{R} & \mathbf{R} & \mathbf{N} & \mathbf{N}\end{array}$ \\
\hline $\begin{array}{l}. \\
\text { S11 }\end{array}$ & (Same schedule for all Ss) & & & \\
\hline
\end{tabular}

There were eight trials per day. The Ss were nun in squads (groups) of 11. All members of a given squad received their daily trials before another squad received their trials. Similarly all members of a squad received a given ordinally-numbered trial before proceeding to the next trial. The order of Ss within a squad was constant, and the alley was swabbed with a damp sponge before each trial of the first $\mathbf{S}$ of a squad. The experimental treatments, represented in Table 1 , were as follows:

Group N: All Ss in the squad received RRNNRRNN on Days 1 and 2 with in a 4-day cycle and the converse schedule, NNRRNNRR, on Days 3 and 4.

Group NC: Same as Group $\mathbf{N}$ except the schedule was a constant RRNNRRNN on all days.

Growp $R$ : Every other $\mathrm{S}$ in the fixed sequence, beginning with the first, received RRNNRRNN on Days 1 and 2 and NNRRNNRR on Days 3 and 4 of the cycle. The remaining, interspersed Ss received the converse schedules.

Group RN: Subjects 1, 5, and 9 in the sequence received RRNNRRNN on Days 1 and 2, and the converse on Days 3 and 4. Subjects 2, 6, and 10 received RRNNRRNN on Days 1 and 4, and the converse on Days 2 and 3. Subjects 3,7, and 11 received RRNNRRNN on Days 3 and 4 and the converse on Days 1 and 2. And Ss 4 and 8 received RRNNRRNN on Days 2 and 3 , and the converse on Days 1 and 4 . Thus, excluding the first $S$ in each group, the intersubject reward contingencies were such that an N-trial of the immediately preceding $S$ was followed always by $N$ for Groups $N$ and $N C$, always by $R$ for Group $R$, and half of the trials by $R$ and half by $N$ for Group RN.

On Day 1 of the study, Ss began a $10-g /$ day feeding regimen. Habituation to the apparatus and reward occurred on Days 9-11, and acquisition began on Day 12. The $S$ was confined to the goal box for $20 \sec$ on all trials. On $R$ trials $S$ had access to a container of $45 \cdot \mathrm{mg}$ food pellets, while on $\mathrm{N}$ trials the container was empty.

\section{RESULTS}

Group mean goal speeds over the last four days of acquisition, excluding the first $S$ of each group, are plotted in Fig. 1 as a function of the goal events of the double alternation cycle. Of primary interest was the marked patterning (fast to $R$, slow to $N$ ) in the response of Groups $\mathrm{N}$ and $\mathrm{NC}$ and the absence of such patterning in Groups R and RN. Analysis of variance indicated that this interaction of Groups by $\mathrm{R}-\mathrm{N}$ events was highly significant, $F(3,36)=56.27, p<.001$. Subsequent analyses (Newman-Keuls procedure) indicated that the patterning was significant for Groups $\mathrm{N}$ and $\mathrm{NC}(\mathrm{p}<.001)$ but not for Groups $R$ and $R N$. In addition, the groups did not differ significantly on $R$ trials, while only Groups $R$ and $R N$ failed to differ $(p<.05)$ on $\mathrm{N}$ trials. This patterning effect was not evident in start or nun measures.

Mean extinction speeds for the goal and run measures are presented in Fig. 2; start speeds, in which the groups differed little, are not presented. In both run and goal measures analysis of variance revealed highly significant effects $(p<.001)$ of Groups, Days, and Groups by Days. Newman-Keuls tests indicated that with respect to mean performance across the extinction phase all groups differed in the run measure and Groups $\mathbf{N}$ and $\mathrm{NC}$ differed from Groups $\mathrm{R}$ and $\mathrm{RN}$ in the goal measure $(\mathrm{p}<.01)$. 


\section{DISCUSSION}

The present data replicate earlier studies (e.g., Ludvigson \& Sytsma, 1967) in demonstrating that strong response patterning is readily achieved when all $S s$ within a squad receive the same event, $R$ or $N$, on a given trial (Groups $N$ and NC). These data extend the previous work in two respects: (1) Response patterning appears stronger and extinction performance weaker when the reward schedule is a constant RRNNRRNN from day to day (Group NC vs N), and (2) no patterning appears when reward always follows an $N$ trial of the immediately-preceding $S$ and altemate preceding $S s$ receive the same event (Group R).

Regarding the odor hypothesis this latter finding indicates that even though the immediately-preceding event provides an unfailing odor cue for the current goal event no discrimination develops if on the second-most preceding (and generally every other) trial the odor cues are reversed.
The implication of this investigation for the methodology of runway studies is a relatively optimistic one: Although odor effects can readily produce a contamination of the effects of experimental treatments, they can be neutralized by a judicious sequence of goal events.

\section{REFERENCES}

LUDVIGSON, H. W., \& SYTSMA, D. The sweet smell of succes: Apparent double alternation in the rat. Psychonomic Science, 1967, 9, 283-284.

McHOSE, J. H., LUDVIGSON, H. W. Differential conditionin with nondifferential reinforcement. Pyychonomic Scieace, 1966, 6, $485-486$.

NOTE

1. This investigation was supported by U.S. Public Heath Research Grant No. MHI3314 from the National Institute of Mental Health.

\section{Choice blas from unilateral cortical depression}

\section{ERNEST G. GREENE ${ }^{l}$ and JOEL ADKINS, University of Oregon Eugene, Ore. 97403 \\ Spreading depression of one cortical hemisphere causes rats to choose the arm of a Y-maze that is ipsilateral to the depression. This choice bias is similar to the effects of unilateral brain lesion. The blas may reflect an asymmetry of perceptual or motor functions produced by the depression.}

There are two principle ways to functionally separate one cortical hemisphere from the other. One method is to cut the connections between the two halves of the brain, and thus produce a "split-brain" animal. In such an animal, the perceptions and memory processes of one hemisphere appear to be completely independent of the other (Sperry, 1964). The other technique is to disrupt temporarily the electrical activity of the cortex on one side by spreading depression. Bures \& Buresová (1960) have reported that memories for complex habits can be stored selectively in one hemisphere by training the animal with the other side depressed. The memory remains on one side unless the animal is given a few trials with both hemispheres undepressed, in which case the memory transfers to the other side as well (Russell \& Ochs, 1961; Ross \& Russell, 1964; Albert, 1966).

Buresová, Bures, \& Beran (1958) have reported that inherent motor dominance (handedness) can be disrupted by unilateral depression. When the cortex contralateral to the preferred hand is depressed, the rat will tend not to use that hand in reaching for food.

Koppman \& O'Kelly (1966) have reported that unilateral depression of cortical function produces a bias in the animal's choice behavior. They found that running speed and number of correct choices of the reinforced goal-arm are enhanced when that arm is on the same side as the cortical depression, but are impaired when the reward is in the arm contralateral to the depressed hemisphere. They suggest that a change in perceptual or motor dominance is responsible for the bias. Though that conclusion may be valid, it cannot be deduced unambiguously from their study. Their animals were trained in a learning task, and were rewarded for choosing one arm of the maze. One might argue that the choice bias could result from anomalies in memory or motivational processes. In fact, there was some reason to suspect that motivational incentive was a factor in determining the choice bias. Koppman (1963) had previously found that when shock was used as the reinforcer, the bias was contralateral to the depressed hemisphereopposite of the bias under food-motivated conditions.

The present research grew out of unpublished observations of choice bias produced by unilateral drug stimulation of cortex and hippocampus. The effects of those treatments could not be produced reliably, and there was reason to suspect that the effects were in fact due to spreading depression. In the present experiment, the unrewarded choices of animals with unilateral spreading depression of the cortex were examined for choice bias. The results complement the research of Koppman \& O'Kelly (1966) and help to clarify the nature of the bias.

\section{METHOD}

The Ss were 20 male albino rats purchased from Rush Laboratories, Beaverton, Oregon. They were 106-111 days old at the time of surgery.

Each $S$ was implanted with a cannula, which was used to inject solutions into the cortex. The cannula was constructed from two pieces of syringe needle, one fitting inside the other. The outer needle (shaft) was made of 21-gauge needle stock, and was cut to a length of $8 \mathrm{~mm}$. The inner needle (probe) was made from 27-gauge needle stock, and was cut slightly longer than the shaft. One end of the probe was crimped to function as a depth stop, and when the probe was seated in the shaft, their tips were flush. The probe could be removed with forceps, but it could not be removed by the $S$.

The operations were done stereotaxically under sodium pentobarbital anesthesia. The cannula was placed relative to bregma: $2.6 \mathrm{~mm}$ posterior, $2.0 \mathrm{~mm}$ to the right, and $3.0 \mathrm{~mm}$ deep. That depth coordinate places the cannula tip about $1 \mathrm{~mm}$ below the surface of the cortex. The cannula was fixed to the skull with bent-wire anchors and dental cement. Each $S$ was allowed at least 4 days of postoperative recovery before being tested.

The Ss were divided into groups of $10 \mathrm{Ss}$ each. In one group, $1 \mu \mathrm{l}$ of $10 \% \mathrm{KCl}$ was injected into the cortex, and in the other, buffered physiological saline solution was injected. A Sage syringe pump was calibrated to deliver this volume in a period of $3 \mathrm{sec}$. The solution was delivered from the syringe through a polyethylene tube to a special "injection probe." Before the $S$ was tested for choice bias, the regular cannula probe was removed from the shaft, the injection probe was inserted, and the solution was injected. 